\title{
What Are the Major Changes in Korean Inflammatory Bowel Disease Surgery?
}

\author{
Chang-Nam Kim \\ Department of Surgery, Eulji University Hospital, Eulji University School of Medicine, Daejeon, Korea
}

\section{See Article on Page 299-305}

Although inflammatory bowel disease (IBD) is a global disease, its genomic, epidemiological, clinical, and therapeutic characteristics vary with ethnicity and geographic location [1]. A study reported that the cumulative probability of a colectomy in Korean ulcerative colitis (UC) patients was much lower than in Western UC patients: the cumulative probabilities of a colectomy in Korean UC patients were $2.0 \%, 2.8 \%$, and $3.3 \%$ after 1,3 , and 5-15 years, respectively [2]. In contrast, in Western UC patients, the cumulative probabilities of a colectomy were $20 \%$ after 5 years, $24 \%$ and $28 \%$ after 10 years, and $45 \%$ after 25 years $[3,4]$. These results suggest that Korean UC patients show a milder course than Western UC patients.

Baek et al. [5] reported very informative data about surgeries for IBD in Korea. Until now, no nationwide data on surgeries for IBD in Korea have been available, but this paper is very helpful for understanding how many operations are performed on patients with UC and Crohn disease (CD) in Korea. Here, I would like to ask two questions: First, why is the proportion of surgery for colorectal cancer increasing in Korean UC patients? Second, does the incidence of laparoscopic surgery increase in Korean patients with IBD?

Baek et al. [5] reported that the proportions of Korean UC patients undergoing colorectal cancer surgery were $27 \%$ in 2009 , $26.2 \%$ in $2010,38 \%$ in $2011,28.1 \%$ in $2012,32.6 \%$ in $2013,56.1 \%$ in 2014 , and $79.8 \%$ in 2015 . These results indicate that the number of Korean UC patients undergoing colorectal cancer surgery

Correspondence to: Chang-Nam Kim, M.D.

Department of Surgery, Eulji University Hospital, Eulji University School of Medicine, 95 Dunsanseo-ro, Seo-gu, Daejeon 35233, Korea

Tel: +82-42-259-1335, Fax: +82-42-259-1335

E-mail: kimcn7@gmail.com

ORCID code: https://orcid.org/0000-0001-7781-9119

(C) 2018 The Korean Society of Coloproctology

This is an open-access article distributed under the terms of the Creative Commons Attribution NonCommercial License (http://creativecommons.org/licenses/by-nc/4.0) which permits unrestricted noncommercial use, distribution, and reproduction in any medium, provided the original work is properly cited. has increased rapidly in recent years.

Why is the proportion of surgery for colorectal cancer increasing in Korean UC patients? First, since the mid-1980s, the number of Korean UC patients has steadily increased [6], as has the number of patients with a longer duration of the disease, which is thought to be related to an increase in the number of patients with colorectal cancer. Chang et al. [7] reported the incidence of newly diagnosed UC in 20,405 patients who underwent sigmoidoscopy and colonoscopy between 1975 and 1992. Until 1987, the annual average was $0.6 \%$, but increased to $1.2 \%$ in $1988,2.2 \%$ in 1989 and $2.7 \%$ in 1991 . In addition, several Korean studies reported that the incidence of patients with UC was increasing: from 0.2 per $10^{5}$ between 1986 and 1988, to 3.1 per $10^{5}$ between 2001 and 2005, and 4.6 per $10^{5}$ between 2006 and 2012 [6, 8, 9]. From 1970 to 2005 , the Korean association for the study of intestinal diseases (KASID) reviewed 7,061 patients with UC, of whom 26 had colorectal cancer: the overall prevalence was $0.37 \%$. In addition, the KASID reported that the estimated cumulative risks of UCassociated colorectal cancer were $0.7 \%, 7.9 \%$, and $33.2 \%$ in patients with UC for 10,20, and 30 years, respectively [10]. This report shows that a longer duration of the disease is closely related to an increased incidence of UC-associated colorectal cancer. Second, the good clinical response to medical treatment of patients with UC and the development of medical treatments for such patients has led to the control of diseases other than cancer, which is thought to be related to the increasing proportion of surgery for colorectal cancer in Korean UC patients. Park et al. [2] reported that of the 304 Korean patients with UC diagnosed for the first time, $97.4 \%$ had clinical remission after first attack. This paper shows good clinical response to medical treatment for UC. The development of anti-tumor necrosis factor agents, including infliximab, adalimumab, and golimumab, has had a major impact on the treatment of patients with UC. Gustavsson et al. [11] reported on the efficacy of infliximab in treating patients with steroid-refractory acute UC: Patients who received a colectomy 3 years later were $50 \%$ (12 of 24 ) in the infliximab group and $76 \%$ (16 of 21 ) in the placebo group $(\mathrm{P}=0.012)$. This paper shows that infliximab has the benefit of lowering the colectomy rate with rescue therapy. Does the incidence of laparoscopic surgery increase in Korean 
patients with IBD? Baek et al. [5] reported that the incidence of laparoscopic surgery was high in Korean patients with IBD. The authors reported that the use of laparoscopic surgery for patients with CD increased by $11.6 \%$ in $2009,18.9 \%$ in $2011,18.5 \%$ in 2013 and 31.2\% in 2015. Laparoscopic surgery for patients with UC has also continued to increase to $23.2 \%$ in $2009,25.7 \%$ in $2011,30.1 \%$ in 2013 and $59.8 \%$ in 2015. The authors reported that the proportions of laparoscopic surgery in 2015 were $31.2 \%$ for patients with CD and 59.8\% for those with UC. These were the incidence rates including anal surgeries for anal fistula and anal abscess. Excluding those operations, the estimated laparoscopy rates in 2015 were $51.5 \%$ for patients with CD and $74.4 \%$ for patients with UC. The relatively low incidence of laparoscopic operations for patients with $\mathrm{CD}$ seems to be associated with more severe complications, such as a severe abscess or fistula, resulting in operations that are more difficult.

The incidence of laparoscopic surgery for patients with colorectal cancer in Korea is high. Park et al. [12] reported nationwide data on 105,305 colorectal cancer patients undergoing resection between 2008 and 2013. The proportion of laparoscopic surgery continued to increase to $42.6 \%$ in $2008,49.5 \%$ in $2009,53.2 \%$ in $2010,57.8 \%$ in $2011,60.8 \%$ in 2012 and $64.7 \%$ in 2013 . The number of robotic surgeries on patients with rectal cancer has increased steadily from 185 cases in 2008, to 200 cases in 2009, 430 cases in 2010, 440 cases in 2011, 455 cases in 2012, and 490 cases in 2013. As can be seen in this report, the incidences of laparoscopic surgery for patients with colorectal cancer and of robotic surgery for patients with rectal cancer are increasing in Korea. Exceptionally, however, hand-assisted laparoscopic surgery (HALS) is being performed by very few surgeons in Korea, and the role of HALS in Korea is underestimated. The reason for mentioning HALS here is that HALS can be a very useful tool for Korean surgeons in IBD surgery, which is much more difficult to perform than colorectal cancer surgery. I use various minimally invasive surgeries such as conventional laparoscopic surgery, HALS, hybrid surgery (combination of laparoscopic and open surgery), and robotic surgery, depending on the characteristics of the disease. A time-consuming surgery, such as a total proctocolectomy for UC or a surgery for $\mathrm{CD}$ with complications, such as perforation, abscess, and fistula, are my personal indications for HALS. The reason for the low rate of laparoscopic surgery for patients with $\mathrm{CD}$ compared to those with UC and colorectal cancer seems to be the difficulty in performing conventional laparoscopic surgery or single-port surgery for patients with $\mathrm{CD}$ who have complications including abscess, firm adhesion, and fistula. In contrast, HALS can be a powerful tool for these difficult cases. I have successfully performed HALS, especially for patients with ileocolic CD with a thickened mesentery and firm adhesion due to complications. In these cases, medial-to-lateral mobilization is often difficult whereas lateral mobilization is relatively easy to perform. If lateral mobilization is successfully performed, the specimens can be taken out through the hand-port device without laparoscopic di- vision of the major vessels including the ileocolic vessels, and the remaining procedures including dissection, cut, and anastomosis can be successfully performed under direct vision.

In conclusion, the rate of surgery for patients with UC-related cancer in Korea is rapidly increasing, and the rate of laparoscopic surgery for patients with $\mathrm{CD}$ is as high as $50 \%$, which is relatively low compared to that for patients with UC or colorectal cancer in Korea. Therefore, the preparation of appropriate treatments for patients with these conditions is needed.

\section{CONFLICTS OF INTEREST}

No conflicts of interest are reported.

\section{REFERENCES}

1. Kim ES, Kim WH. Inflammatory bowel disease in Korea: epidemiological, genomic, clinical, and therapeutic characteristics. Gut Liver 2010;4:1-14.

2. Park SH, Kim YM, Yang SK, Kim SH, Byeon JS, Myung SJ, et al. Clinical features and natural history of ulcerative colitis in Korea. Inflamm Bowel Dis 2007;13:278-83.

3. Leijonmarck CE, Persson PG, Hellers G. Factors affecting colectomy rate in ulcerative colitis: an epidemiologic study. Gut 1990; 31:329-33.

4. Langholz E, Munkholm P, Davidsen M, Binder V. Course of ulcerative colitis: analysis of changes in disease activity over years. Gastroenterology 1994;107:3-11.

5. Baek SJ, Lee KY, Song KH, Yu CS; Inflammatory Bowel Disease (IBD) Study Group of the Korean Society of Coloproctology. Current status and trends in inflammatory bowel disease surgery in Korea: analysis of data in a nationwide registry. Ann Coloproctol 2018;34:299-305.

6. Yang SK, Hong WS, Min YI, Kim HY, Yoo JY, Rhee PL, et al. Incidence and prevalence of ulcerative colitis in the Songpa-Kangdong District, Seoul, Korea, 1986-1997. J Gastroenterol Hepatol 2000;15:1037-42.

7. Chang DK, Lee KL, Kim JG, Kim YT, Jung HC, Song JS, et al. Follow-up of ulcerative colitis: short-term outcome to medical treatment and relapse rates. Korean J Gastroenterol 1994;26:90718.

8. Yang SK, Yun S, Kim JH, Park JY, Kim HY, Kim YH, et al. Epidemiology of inflammatory bowel disease in the Songpa-Kangdong district, Seoul, Korea, 1986-2005: a KASID study. Inflamm Bowel Dis 2008;14:542-9.

9. Kim HJ, Hann HJ, Hong SN, Kim KH, Ahn IM, Song JY, et al. Incidence and natural course of inflammatory bowel disease in Korea, 2006-2012: a nationwide population-based study. Inflamm Bowel Dis 2015;21:623-30.

10. Kim BJ, Yang SK, Kim JS, Jeen YT, Choi H, Han DS, et al. Trends of ulcerative colitis-associated colorectal cancer in Korea: a KASID study. J Gastroenterol Hepatol 2009;24:667-71. 
11. Gustavsson A, Järnerot G, Hertervig E, Friis-Liby I, Blomquist L, Karlén P, et al. Clinical trial: colectomy after rescue therapy in ulcerative colitis - 3-year follow-up of the Swedish-Danish controlled infliximab study. Aliment Pharmacol Ther 2010;32:984-9.
12. Park SJ, Lee KY, Lee SH. Laparoscopic surgery for colorectal cancer in Korea: nationwide data from 2008 2013. J Minim Invasive Surg 2015;18:39-43. 